\title{
Formulation of Eel (Monopterus albus) extract membranes for wound dressing using plasticizers
}

\author{
Febriyenti*, Rahmi Nofita, \& Khalidazia \\ Faculty of Pharmacy, Andalas University, Limau Manis Pauh, Padang City, West Sumatera, 25163
}

\begin{abstract}
The types of wound dressing will affect wound healing processes. The membrane is one of the potential wound dressing that can maintain the moisture of the wound surface. The eel extract as an active ingredient could be added to the membrane formula to accelerate wound healing. This study aimed to formulate eel (Monopterus albus) extract membranes for wound dressing using some plasticizers. Polyvinyl alcohol (PVA) 146,000 was used as the polymer, while glycerol, propylene glycol, and polyethylene glycol (PEG) 400 were used as the plasticizers. Methylparaben and propylparaben were added as preservatives. Evaluations included thickness, water vapor permeability, and mechanical properties of the membranes that consisted of tensile strength, elongation at break, and Young's modulus were performed. The result showed that the use of different types of plasticizers affected the mechanical properties of the eel extract membrane. The formula that used glycerol as the plasticizer produced membranes with the best water vapor permeability and mechanical properties.
\end{abstract}

Keywords: eel; Monopterus albus; extract; membrane; wound dressing; plasticizer.

\section{Introduction}

The treatment of wound in the past was carried out by allowing the wound to dry and form a hard layer, which would then peel off by itself. However, over the advancement in science and technology, the treatment of the wound has changed. It is known that the wound heal more rapidly if the moist is covering the wound as the wound dressing. Traditionally, gauzes made of cotton were used as wound dressings. There are some types of wound dressings such as hydrocolloid, hydrogel, foam, and semipermeable adhesive membrane [1,2]. The membrane is a preferable one because it is transparent thus easy to observe the level of healing, comfortable to use on the elbows and knees because it is elastic and not easily torn. In addition, membranes are also permeable to oxygen and water vapor to allow skin respiration $[2,3]$.

Membranes are pharmaceutical preparations that have thicknesses between micrometers to millimeters andmade by various methods using one or more polymers. Polymers are the main ingredient of the membrane. Meanwhile, plasticizer is usually added to form elastic and flexible membranes. The plasticizer can reduce intermolecular forces and increase the flexibility of membranes by widening the space of molecules and weakening the hydrogen bonds of polymer chains. The amount of plasticizer used can affect the mechanical properties of the membrane. In a previous study [4], the honey membrane was formulated with glycerol, polyethylene glycol, and propylene glycol as plasticizers, which are from poly alcohol groups $[5,6]$.

Membranes with a homogeneous polymeric bonding structure are used to treat damaged skin areas and generally protect injured areas from external factors $[7,8]$. Aside from being wound dressing, the membrane can also function to help wound healing with the presence of active ingredients contained in the membrane. Several previous studies showed that natural ingredients were added as active substances into the membrane formula such as chitosan [9], haruan (Channa striatus) extract [10], and honey [4].

Eels are Pisces class animals that contain many ingredients useful for humans. These include omega-3 and omega- 6 fatty acids. The content of arachidonic acid and DHA in an eel body is 8.25 and $6.21 \mathrm{~g}$ per $100 \mathrm{~g}$ fat, respectively [11]. Based on a previous study by Febriyenti et al. [12], the fatty acid composition of eel extracts was dominated by oleic acid (19.7\%), palmitic acid (18.7\%), pentadecanoic acid $(15.81 \%)$ and octadecanoic acid (4.87\%). Omega-3 and omega-6 fatty acids play an important role in the wound healing process. Omega-3
Article history

Received: 26 Des 2019 Accepted: 2 April 2020 Published: 30 April 2020

Access this article

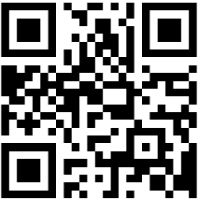


Table 1. Formulae of eel (Monopterus albus) extract membrane

\begin{tabular}{lccc}
\hline \multirow{2}{*}{ Ingredients } & \multicolumn{3}{c}{ Formula (\%) } \\
\cline { 2 - 4 } & F1 & F2 & F3 \\
\hline Eels extract & 10 & 10 & 10 \\
PVA & 10 & 10 & 10 \\
Glycerol & 3 & - & - \\
Propylene glycol & - & 3 & - \\
PEG 400 & - & - & 3 \\
Methylparaben & 0.1 & 0.1 & 0.1 \\
Propylparaben & 0.02 & 0.02 & 0.02 \\
Distilled water up to & 100 & 100 & 100 \\
\hline
\end{tabular}

fatty acids act as anti-inflammatory agents that work to inhibit eicosanoid production [13]. Therefore, eels can be used as additional nutrients to accelerate the wound healing process. The present study aimed to formulate the eel extract membrane with a variety of plasticizers in order to evaluate the effect of the type of plasticizers on thickness, permeability, and mechanical properties of the membranes.

\section{Materials and Methods}

Materials

Eels were purchased from Bukittinggi, West Sumatera, Indonesia. Eel extract was prepared, according to Febriyenti et al. [12]. PVA 146,000 was bought from VWR International, Belgium. Glycerol, propylene glycol, PEG 400, methylparaben, and propylparaben were acquired from R\&M Chemicals, UK. Distilled water was purchased from Bratachem, Indonesia. All chemicals were used without further purification.

\section{Preparations of Eels Extract Membranes}

PVA was prepared by the hot mechanical method $[4,14,15]$. PVA was dissolved in hot distilled water. Eel extract, methylparaben, propylparaben were dispersed in glycerol, propylene glycol or PEG 400, and then mixed with PVA solution using Ultra turrax at 10,000 rpm for 15 minutes $[4,16,17]$. The formulae can be seen in Table 1 . Furthermore, the membrane was prepared using casting techniques. Some of the liquid membrane formulae were poured into the glass mold (size $20 \mathrm{~cm}$ x $20 \mathrm{~cm}$ ), then allowed to dry at room temperature for approximately 24 hours $[4,10,18]$.

\section{Membrane Thickness}

The membrane thicknesses were measured based on the method in previous studies $[4,10,19,20]$ by using a micrometer (Digimatic micrometer, Mitutoyo, Tokyo, Japan).

\section{Water Vapor Permeability of The Membrane}

The rates of water vapor permeability of the membrane were determined using the method described in USP XXIV [21]. The method was also used in previous studies $[4,10]$.

\section{Mechanical Properties Measurements}

The mechanical properties of the membrane were measured using the same method of previous studies [4,10,22]. A texture analyzer (TA.XT2, Stable Micro System, Haslemere, Surrey, UK) was used to determine

Table 2. Thickness and water vapor permeability of eel extract membranes

\begin{tabular}{ccc}
\hline Formula & Thickness $(\mathrm{mm})$ & Water vapor permeability $(\mathrm{mg} / \mathrm{L} /$ day $)$ \\
\hline F1 & $0.047^{\mathrm{b}} \pm 0.005$ & $1981^{\mathrm{b}} \pm 205$ \\
F2 & $0.043^{\mathrm{a}} \pm 0.001$ & $995^{\mathrm{a}} \pm 328$ \\
F3 & $0.043^{\mathrm{a}} \pm 0.002$ & $631^{\mathrm{a}} \pm 109$ \\
\hline
\end{tabular}


Table 3. Formulae of eel (Monopterus albus) extract membrane

\begin{tabular}{|c|c|c|c|}
\hline \multirow{2}{*}{ Ingredients } & \multicolumn{3}{|c|}{ Formula (\%) } \\
\hline & Tensile strength $\left(\mathrm{N} / \mathrm{mm}^{2}\right)$ & Elongation at break (\%) & Young's modulus $\left(\mathrm{N} / \mathrm{mm}^{2}\right)$ \\
\hline $\mathrm{F} 1$ & $25.96^{a} \pm 0.91$ & $256^{\mathrm{a}} \pm 23.2$ & $10.20^{b} \pm 1.31$ \\
\hline F2 & $26.02^{\mathrm{a}} \pm 0.37$ & $315^{b} \pm 9.2$ & $8.26^{a} \pm 0.14$ \\
\hline F3 & $24.70^{\mathrm{a}} \pm 1.02$ & $313^{b} \pm 15.9$ & $7.89^{a} \pm 0.59$ \\
\hline
\end{tabular}

tensile strength value and elongation at the break of the membrane. Young's Modulus (E) was calculated using the equation in Martin et al. [23].

\section{Statistical Analysis}

The data were presented as mean \pm SD and analyzed statistically by one-way analysis of variance (ANOVA) to compare the results using SPSS software (version 15, USA). Post-hoc Tukey's Honestly Significant Difference (Tukey-HSD) test was applied when there was a statistically significant difference $(\mathrm{P}<0.05)[9,24]$.

\section{Results and Discussion}

The eel extract membranes formulated in this study function as a wound dressing to keep the wound moist and prevent secondary infection by microorganisms. Membranes have several advantages, including being transparent and permeable to water vapor, allowing the skin tissue respiration. Membranes are also comfortable to use on elbows and knees because they are elastic and not easily torn [1-3]. Based on the previous study [4], PVA is the best polymer that could produce a transparent membrane. Herein, PVA was used as a polymer to form the eel extract membrane. Meanwhile, glycerol, propylene glycol, and PEG 400 were used as plasticizers.

Results of membrane thickness and water vapor permeability tests are tabulated in Table 2 . The formula that used glycerol as the plasticizer had a significantly different membrane thickness than the other formula. Different types of plasticizers are reported to affect the thickness and mechanical properties of the membrane $[4,10]$. The ideal wound dressing has to be permeable to water vapor that could control the moisture on the surface of the wound $[1,3]$. According to USP XXIV [21], materials or membranes with water vapor permeability more than 2000 $\mathrm{mg} / \mathrm{L} /$ day are categorized as permeable. The results in Table 2 show that F1 was the only formula that had water vapor permeability close to $2000 \mathrm{mg} / \mathrm{L} /$ day.

The ideal wound dressing should be sturdy but pliable and elastic $[9,25,26]$. When a wound dressing is applied to the wound, it should not be easily separated and damaged. The results of mechanical properties in Table 3 show that all formulae have good tensile strength and elongation, but F1 has a better Young's modulus value.

\section{Conclusion}

This study concludes that the formula F1 that uses glycerol as a plasticizer produced membranes with good water vapor permeability and mechanical properties.

\section{References}

[1]. dos Santos KSCR, Coelho JFJ, Ferreira P, Pinto I, Lorenzetti SG, Ferreira $\mathrm{El}$, et al. Synthesis and characterization of membranes obtained by graft copolymerization of 2-hydroxyethyl methacrylate and acrylic acid onto chitosan. Int J Pharm. 2006;310(1-2):37-45. https://doi. org/10.1016/j.ijpharm.2005.11.019

[2]. Boateng JS, Matthews KH, Stevens HNE, Eccleston GM. Wound Healing Dressings and Drug Delivery Systems: A Review. J Pharm Sci. 2008;97(8):2892-923. https://doi.org/10.1002/jps.21210

[3]. Cockbill, S. M. E. (Ed.) 2007 Encyclopedia of Pharmaceutical Technology (Third edition ed., Vols. 2). New York: Informa Healthcare. 1023-37.

[4]. Febriyenti, Fitria N, Mohtar N, Umar S, Noviza D, Rineldi S, et al. Honey gel and film for burn wound. Int J Drug Deliv. 2014;6(1):1-6. https://doi.org/10.5138/ijdd.v6i1.1308

[5]. Cervera MF, Heinämäki J, Krogars K, Jörgensen AC, Karjalainen $\mathrm{M}$, Colarte $\mathrm{Al}$, et al. Solid-state and mechanical properties of aqueous chitosan-amylose starch films plasticized with polyols. AAPS PharmSciTech. 2004;5(1):109-14. https://doi.org/10.1208/ pt050115

[6]. Suppakul, P. Plasticizer and Relative Humidity Effects on Mechanical Properties of Cassava Flour Films. Kasetsart University, Bangkok; 2006.

[7]. Verma S, Kumar S, Gokhale R, Burgess DJ. Physical stability of nanosuspensions: Investigation of the role of stabilizers on Ostwald ripening. Int J Pharm. 2011;406(1-2):145-52. https://doi. org/10.1016/j.ijpharm.2010.12.027

[8]. Stashak TS, Farstvedt E, Othic A. Update on wound dressings: Indications and best use. Clin Tech Equine Pract. 2004;3(2):148-63. https://doi.org/10.1053/j.ctep.2004.08.006

[9]. Peh K, Khan T, Ch'ng H. Mechanical, bioadhesive strength and biological evaluations of chitosan films for wound dressing. J Pharm Pharm Sci. 2000;3(3):303-11.

[10]. Febriyenti, Noor AM, Baie SBB. Mechanical properties and water vapour permeability of film from Haruan (Channa striatus) and Fusidic acid spray for wound dressing and wound healing. Pak J Pharm Sci. 2010;23(2):155-9. 
[11]. Razak ZKA, Basri M, Dzulkefly K, Razak CNA, Salleh AB. Extraction and Characterization of Fish Oil from Monopterus Albus. Malaysian J Anal Sci. 2001;7(1):217-20.

[12]. Febriyenti, Almahdy A, Mulyani D. Amino acids and fatty acids profiles of eel (Monopterus albus) water extracts. Rasayan J Chem. 2019;12(3):1591-4. https://doi.org/10.31788/RJC.2019.1234071

[13]. Williams JZ, Barbul A. Nutrition and wound healing. Surg Clin North Am. 2003;83(3):571-96. https://doi.org/10.1016/S00396109(02)00193-7

[14]. Shivhare UD, Jain KB, Mathur VB, Bhusari KP, Roy AA. Formulation development and evaluation of diclofenac sodium gel using water soluble polyacrylamide polymer. Dig J Nanomater Biostructures. 2009;4(2):285-90.

[15]. USP. The United States Pharmacopeia XXX- The National Formulary XXV. Rockville: United States Pharmacopeial Convention, Inc; 2007.

[16]. Febriyenti, Noor AM, Baie S. Formulation of aerosol concentrates containing Haruan (Channa striatus) for wound dressing. Malaysian J Pharm Sci. 2008;6(1):43-58

[17]. Febriyenti, NoorAM, BaieSBB. Physical evaluations of Haruan spray for wound dressing and wound healing. Int J Drug Deliv. 2011;3(1):11524. https://doi.org/10.5138/ijdd.2010.0975.0215.03061

[18]. Fetisova NI, Tsetlin VM. Main group of parameters for evaluating film-forming properties in aerosol packages for the treatment of an operation field and for the sealing of wounds. Pharm Chem J. 1976;10(8):1071-5. https://doi.org/10.1007/BF00758099

[19]. Yoo J-W, Dharmala K, Lee $\mathrm{CH}$. The physicodynamic properties of mucoadhesive polymeric films developed as female controlled drug delivery system. Int J Pharm. 2006;309(1-2):139-45. https://doi. org/10.1016/j.ijpharm.2005.11.020
[20]. Macleod GS, Fell JT, Collett JH. Studies on the physical properties of mixed pectin/ethylcellulose films intended for colonic drug delivery. Int J Pharm. 1997;157(1):53-60. https://doi.org/10.1016/S0378 5173(97)00216-0

[21]. USP. Containers - Permeation United States Pharmacopoeia, 1936 1937. Rockville: United States Pharmacopeial Convention; 2000.

[22]. García MA, Pinotti A, Martino M, Zaritzky N. Electrically treated composite FILMS based on chitosan and methylcellulose blends. Food Hydrocoll. 2009;23(3):722-8. https://doi.org/10.1016/i. foodhyd.2008.06.008

[23]. Martin A, Bustamante P, Chun, AHC. (Eds.). Physical Pharmacy (Fourth ed.). Baltimore: Lippincott Williams \& Wilkins; 2001.

[24]. Petersen RG. Design and Analysis of Experiments. New York: Marcel Dekker, Inc.; 1985. p. 72-111.

[25]. Nagarsenker MS, Hegde DD. Optimization of the mechanical properties and water-vapor transmission properties of free films of hydroxypropylmethylcellulose. Drug Dev Ind Pharm. 1999;25(1):958. https://doi.org/10.1081/DDC-100102147

[26]. Sezer AD, Hatipoglu F, Cevher E, Oğurtan Z, Bas AL, Akbuğa J. Chitosan film containing fucoidan as a wound dressing for dermal burn healing: Preparation and in vitro/in vivo evaluation. AAPS PharmSciTech. 2007;8(2):E94-101. https://doi.org/10.1208 pt0802039

Copyright $\odot 2020$ The author(s). You are free to share (copy and redistribute the material in any medium or format) and adapt (remix, transform, and build upon the material for any purpose, even commercially) under the following terms: Attribution - You must give appropriate credit provide a link to the license, and indicate if changes were made. You may do so in any reasonable manner, but not in any way that suggests the licensor endorses you or your use. ShareAlike - If you remix, transform, or build upon the material, you must distribute your contributions under the same license as the original (https://creativecommons.org/licenses/by-sa/4.0/) 